Article

\title{
Imperfect Data, Art Markets and Internet Research
}

\author{
Hans J. Van Miegroet *, Kaylee P. Alexander $\mathbb{D}$ and Fiene Leunissen $\mathbb{D}$ \\ Duke Art, Law \& Markets Initiative (DALMI), Department of Art, Art History \& Visual Studies, \\ Duke University, Durham, NC 27708, USA \\ * Correspondence: hvm@duke.edu
}

Received: 30 April 2019; Accepted: 20 June 2019; Published: 26 June 2019

check for updates

\begin{abstract}
The sheer volume of data generated on the Internet has reached unprecedented numerical heights and has enabled new data-driven methodologies to study art and its markets. Yet, this type of data-driven research has also generated several unexpected methodological constraints for art markets researchers, particularly due to informational asymmetry. This observation is related to how various players on the Internet make data available, as well as summarize, transmit, gather, and access those data globally. It is not our ambition to present another historiography of art markets research, past and present. Rather, and in keeping with the theme of this special issue, we would like to focus on a few key constraints related to data-driven, contemporary art markets research, the Internet, and the structural recurrence of imperfect data. This contribution focuses on four areas of Internet research and its methods that are particularly problematic for researchers today, namely (1) auctions and online auctions; (2) dealers and galleries; (3) art indices; and (4) art fairs.
\end{abstract}

Keywords: art markets; informational asymmetry; data constraints; online auctions; art indices; Internet galleries; art fairs

\section{Introduction}

At present, online data about art, its production, its history, reception, sales and consumption are abundantly available on all kinds of Internet platforms. Advanced research on both historical and contemporary art markets has embraced the many opportunities this medium and the resulting data explosion has offered, yet this has not always resulted in improvements to informational transparency, here defined as the optimal level of availability, accessibility, and reliability of data regarding art and its markets, broadly defined. The question immediately arises as to why we should even care or expect the Internet to reduce the information asymmetry of art markets; or conversely, whether or not the Internet needs to mitigate agency issues between information providers-opaque or not—and end-users, regardless of whether or not those users are researchers. ${ }^{1}$ Likewise, the question of how to mediate deficiencies towards higher levels of market transparency, permitting researchers to observe previously unavailable data, is of increasing need of discussion.

Visual artists, not art markets scholars, were among the first to experiment with new digital platforms. Since the early 1990s, the online presence of artists and their work has never been more visible and significant than on the Internet (McLaughlin 1996). Artists are represented in every arena of network activity: electronic mailing lists, websites, and social media (especially Instagram), particularly used by emerging artists, museums, galleries and dealers among others (see for instance, Soboleva 2015; Kazakina 2016). Additionally, groups concerned with policy issues and arts advocacy, and art price

1 For a substantial overview of the literature focused on many cyberlaw issues with intermediaries, including cyberlaw deficiencies, how to resolve these, and how to address Internet asymmetry, see (Pasquale 2010). 
indices have set up all kinds of digital and data-driven media platforms to reach a broader, more diversified audience. Museums, auction houses, dealers, galleries and art fairs have followed suit, as have art markets constituencies with scholarly and/or business-oriented objectives. ${ }^{2}$

Data-driven research on art markets and its attendant new methodologies are historically the province of economists, cultural economists, social historians and sociologists. ${ }^{3}$ These studies, in turn, have opened many new perspectives for historians, art historians and a new breed of hybrid, cross-disciplinary researchers interested in art markets as objects of inquiry, here conveniently referred to as art markets scholars. For this new breed of researchers, the Internet has been the prime locus to gather data on historical and contemporary art markets in the aggregate. The sheer volume of data generated on the Internet has reached unprecedented numerical heights and has enabled new data-driven methodologies to study art and its markets. Yet, this type of data-driven research has also generated several unexpected methodological constraints for art markets researchers, particularly due to informational asymmetry. This observation is related to how various players on the Internet make data available, as well as summarize, transmit, gather, and access those data globally.

It is not our ambition to present another historiography of art markets research, past and present. Rather, and in keeping with the theme of this special issue, we would like to focus on a few key methodological constraints related to data-driven, contemporary art markets research, the Internet and the structural recurrence of imperfect data. This contribution focuses on four areas of Internet research and its methods that are particularly problematic for researchers today, namely (1) auctions and online auctions; (2) dealers and galleries; (3) art indices; and (4) art fairs.

\section{Auctions and Online Auctions}

At present, a sizable amount of data-driven research focuses on sales results obtained from auctions and online auctions (Ashenfelter and Graddy 2006). The choice to focus on prices fetched at auction, which can also be interpreted in terms of marginal willingness to pay, or a proxy for a buyer's preference, is related to the long-standing debate in economics on the theory of value. At the end of the nineteenth century, this shifted towards a theory of price, which is foundational for many present-day economic theories that rationalize art and art prices as part of all kinds of professional investment vehicles (Hutter and Shusterman 2006). Herein lies the rationale for the increasing the amount of price information mediated through the Internet today in an attempt to turn artworks into investment vehicles. As a result of this process of connecting art markets with financial markets, the Internet is increasingly used as a platform to distribute price information and promote market and organizational devices from the financial world. As such, the Internet, as an information platform, is continuously mediating between financial and art constituencies, sometimes referred to as the "financialization" of art and art markets (Velthuis and Coslor 2012). The quality of this mediation, of course, depends on the quality of the players involved. On the surface, all of this seems to create new opportunities for art markets research. However, these data have not been constructed for this purpose, and this has critical repercussions for how we approach contemporary art markets as objects of inquiry. While, auction houses, for example, consistently publish their sales results online, these data have not been structured (at least in its public-facing form) for aggregate analysis. E-commerce sites for art, on the other hand, seldom make all of their past results available, or may even publish price information that is not independently verifiable due to their status as third-parties.

2 An appropriate example of art markets studies with imperfect data, but with a distinct historical dimension is Brill's Studies in the History of Collecting $\mathcal{E}$ Art Markets, which is a peer-reviewed book series dedicated to original scholarship on the social, cultural, and economic mechanisms underlying the circulation of art and markets. For an overview of their Art \& Market Publications, see: https://brill.com/view/serial/HCAM?lang=en.

3 For a good introduction to cultural economics and its objects of inquiry, see (Frey 2003; Towse 2011; Ginsburgh and Throsby 2006, 2014). 
Another long-standing debate in the economics of art and culture is that the theory of value in economics is not equipped to adequately connect economic to cultural value (Throsby and Zednik 2014). In fact, the methods of economic valuation-including the heterogeneity of art, or its illiquidity-are far more quantitatively advanced as compared to those studies concerned with cultural value assessment. The consequence for online (and offline) research is that economic value, or rather, the theory of price, has become one of the preferred approaches among many scholars. In past years we have witnessed a rise of all kinds of relational databases, art sales indices, new online auction platforms, as well as applied research on price dynamics, online bidding behavior, and so on. ${ }^{4}$

Current and aggregate data on auction markets, both offline and online, can be hard to come by. While auction houses publish their results on online, they organize these data by individual auction events, and it is thus not indexed in a way that would allow visitors to the site to download the aggregate data. The result is that researchers, as well as active participants in art markets (i.e., dealers, collectors, financial institutions, etc.), often rely on private companies' indices, databases, and reports out of necessity.

For instance, the Blouin Art Sales Index (BASI) gives access to over 9 million records from 425 artists and 3000 auction houses. Likewise, ArtNet, AskArt, and other private entities offer subscription or pay-per-search databases of auction results gathered from auction houses of varying scales worldwide. Platforms such as these, however, have also not been built for the use of data in the aggregate, and most often serve participants in art markets as supplementary tools for art advisory and appraisal, rather than art markets scholars seeking to advance research into these markets. There is no "download" button that furnishes the user with the raw data to reproduce these indices or perform new analyses. Though BASI, for instance, offers customized reports, produced by their team of data-scientists and art markets experts using their database, these services are again geared towards appraisers, collectors and dealers (Blouin Art Sales Index BASI). The lack of transparency and public availability of the data used in these and other art markets reports need to be critically considered to avoid taking the information therein at face value.

In addition, scholars engaged in data-driven research, including anthropology, art history, history, sociology and cultural studies have also recognized that there are both aesthetic and commercial dimensions to the value of artworks (Throsby and Zednik 2014, p. 83). Recent attention to "external effects" has also opened new ways of interpreting artistic value in a manner consistent with economic theory (Hutter and Shusterman 2006). Despite the ever mounting availability of online data, the study of the history of art markets has not received the same amount of scholarly attention one would expect in art history and cultural economics. ${ }^{5}$ Though here too, new hybrid art history-economics methodologies are deployed based on empirical historical evidence in the aggregate, or more creative approaches to dealing with imperfect data, with or without regression analyses. ${ }^{6}$ It remains, however, a critical question as to whether or not we can move beyond the hype of new media expectations and generate more appropriate avenues of investigation to better grasp possible changes amongst actors within the contemporary art world (Arora and Vermeylen 2013).

In this digital age of abundant, yet imperfect data, online statements surface regularly praising the unrestricted availability of information. An almost Leibnizean optimism reigns supreme or how data and digital connectedness has created a global art market mediated through a variety of Internet platforms. Though it is true that participants online produce all kinds of new knowledge about art and

4 One example are the Mei-Moses price indeces now owned by Sotheby's; for a model study on online bidding behavior, see (Pownall and Wolk 2013).

5 A very useful source as a broad introduction of scholarship on art markets in the aggregate with ample references to past literature is (Hulst 2017).

6 On developing new methdologies using imperfect data to study historical art makets, see for instance (Vermeylen 2006), and a more collective approach in (De Marchi and Van Miegroet 2006b). In addition, see (Velthuis 2011). A more recent, and inspiring example of the study of historical art markets with imperfect data and innovative research strategies is (Van Ginhoven 2016). 
markets, the question remains whether this knowledge is always as empirically testable as it seems to be, not to mention whether or not the data are reliable or have been retrieved with opaque gathering methods and algorithms. Even when we use online information that appears bona fide, such as online auction results posted by Sotheby's or Christie's, or reputed price indices created by Mei and Moses or Blouin, a few caveats are in order. We will discuss art indices a bit further.

Reputable auction houses, such as Christie's and Sotheby's not only have distinct web presences but have also organized online auctions since 2012 (Christie's) and 2016 (Sotheby's). ${ }^{7}$ The phenomenon of online auctions in combination with the Internet data explosion, is seen as dismantling the age-old buyer-seller paradigms, introducing new business models, and creating a digitally connected global art market. Apart from the fact that a singular, global art market does not exist, studies in the history of art markets (plural) has shown that such markets emerge in very specific locations at very specific points in time with locally determined constraints, taste preferences and regulatory environments (De Marchi and Van Miegroet 2006a). Several types of art markets can even coexist in the same geographical location and at the same point in time. Even today, a wide variety in local art markets in various stages of development can be observed. These can be dealer or collector dominated, suffer from informational asymmetry, or be inefficient due to a lack of substitutes and the presence of monopolistic or duopolistic positions.

Though the notion of an "online auction sale" may create all kinds of transparency expectations, including that of a digitally mediated global market, there is, in fact, no such thing as a global market and the local component should not be neglected (Velthuis 2013). To repeat, all art markets are local and in various stages of development; factoring in the global component has merit when considering that local art markets are often connected globally through the Internet. This more nuanced understanding of art markets will help to create some epistemological and methodological clarity in critical, scholarly research using online markets data in the aggregate.

Fairly recently, in May 2017, Christie's began releasing the results of their online auction sales, with Sotheby's following suit in October of that year. Another point of methodological confusion is the recurring notion of the "online sale." It is critical to make a clear distinction between what is coined as an "online-only" sale, and what is considered an auction sale that has an online presence and/or the possibility of online bidding. Online-only sales should only refer to sales for which no bidding occurs in the auction house itself. When compared over the course of the entire 2018 auction year, sales online and offline at Christie's and Sotheby's were geographically located in New York, London, Hong Kong, each location with their associated regulatory constraints and currencies. In addition, Christie's continues to host in-person viewing hours for many of their "online-only" sales, particularly for those sales containing fine art objects. This suggests that online-only sales are, in fact, not exclusively as online as they claim to be. The term is misleading, for they have still a distinct brick-and-mortar component, both in terms of market-specific currencies and regulatory environments, not to mention the ability to view artworks in person and in a brick-and-mortar setting, before any transacting takes place online. At best, these auction sales represent a hybrid model that should be defined as such to avoid confusion.

As shown in Table 1, of all lots sold at Christie's New York, London and Hong Kong in 2018 (those deemed online-only, as well as those taking place offline), $21.3 \%$ of lots were sold through these hybrid online-only sales, which only accounted for $1.8 \%$ of the total sales revenue in that year. ${ }^{8}$

7 While the first online-only sale at Christie's occurred in 2012, they did not begin reporting their results until May 2017; they began offering online bidding several years prior to 2012. Sotheby's, on the other hand, announced in 1999 a plan to create an online marketplace, but shut down this plan in 2003. In 2016 Sotheby's partnered with the Invaluable marketplace to manage both their online bidding and online-only sales. For more information on the development of online art markets, see (Pownall 2017).

8 (Ali et al. 2019). The share of online-only lots and revenue for Christie's is comparable to the conclusions drawn for South Korean auction markets in a DALMI Working Paper by Yoon et al. (2018). 
Table 1. Auction results of Christie's New York, London, and Hong Kong (2018). Source: (Ali et al. 2019).

\begin{tabular}{ccccc}
\hline Location & \# of Lots & \% of Total Lots & Total Revenue (incl. BP) & \% Total Revue \\
\hline Online-Only & 7149 & $21 \%$ & $\$ 64,635,251$ & $2 \%$ \\
New York & 10,439 & $31 \%$ & $\$ 1,648,322,934$ & $47 \%$ \\
Hong Kong & 4592 & $14 \%$ & $\$ 740,230,005$ & $21 \%$ \\
London & 11,322 & $34 \%$ & $\$ 1,059,447,683$ & $30 \%$ \\
Total & $\mathbf{3 3 , 5 0 2}$ & $\mathbf{1 0 0} \%$ & $\$ 3,512,635,873$ & $\mathbf{1 0 0} \%$ \\
\hline
\end{tabular}

So far, there have been six "online-only" sales at Christie's (London and New York) in March 2019. Of these six sales, five sales have offered brick-and-mortar viewing times for all or for a selection of objects being offered for sale. ${ }^{9}$ The online auction calendar at these houses also closely follows patterns of the offline, brick-and-mortar auction calendar. To illustrate, sales of Contemporary and Modern Art are offered in the spring, although, as observed earlier, their sales results represent a lower segment of this auction market. ${ }^{10}$

As the majority of sales data for online art auctions was not available until recently, and data regarding online art sales outside of auction markets is not widely available, previous research into this subject has been based predominately on surveys of buyers and sellers. One of the prime movers in the field of online art markets research has been Hiscox, an international insurance company headquartered in Bermuda, which published its first report in 2013. ${ }^{11}$ The Hiscox reports rely mostly on data collected from surveys of international art buyers subscribed through ArtTactic's client mailing list, and from a group of international art galleries operating in the contemporary art market. ${ }^{12}$ The amount of survey respondents has varied over the years, with 130 collectors and 48 galleries in 2013, and 706 collectors and 128 galleries in 2019. However, these numbers of respondents remain quite small given the number of art markets participants that exist worldwide (there are well over 1000 galleries in New York City alone). This selection becomes even more problematic when looking at the characteristics of these respondents. For instance, in $201954 \%$ of respondents stated that they spend less than $£ 5000$ per year on fine art and collectibles. ${ }^{13}$ Hiscox, however is not the only report currently available that attempts to predict new developments in the online art market. In 2017 TEFAF published its "Online focus" as a supplement to their Art Market Report. In the data overview for this supplement we see, however, that this report is, too, based on the data collected by Hiscox.

The consequences of data selection methodologies have become increasingly apparent, especially as evidenced in 2016, when the economist Clare McAndrew (who had previously authored the art market reports published by TEFAF), was recruited to write the reports for Art Basel. With this changeover, the 2017 TEFAF Art Market Report was assumed by finance professor, Rachel Pownall. However, the two scholars' varying methodologies for calculating the global value of the art market presented much cause for discussion. ${ }^{14}$ This resulted in the decision of TEFAF to discontinue their annual art market reports, and instead produce a series of in-depth studies on various subjects (Gerlis 2018).

9 Auction Results. Christie's, stable URL: https://www.christies.com/results?sc_lang=en\&lid=1.

10 Sale \#18084 at Christie's ("Matisse on Paper: Prints and Drawings from the Estate of Jacquelyn Miller Matisse") took place from 21 February to 1 March 2019. The sale included 28 lots and brought in a total revenue of 891,250 USD (including the Buyer's Premium). Additionally, Sale \#16753 at Christie's ("Picasso Ceramics Online") took place from 22 February to 1 March 2019. This sale included 114 lots and brought in a total revenue of 1,458,250 GBP (including the Buyer's Premium).

11 Since 2013, Hiscox has released reports on the online art market annually. While the numbers of respondents in 2019 was greater than 2013, the numbers of respondents to the Hiscox survey in recent years has decreased. Between the 2018 and 2019 report, for example the numbers of respondents decreased from 831 collectors and 130 galleries to 706 collectors and 128 galleries. All past reports can be accessed here: https://www.hiscox.co.uk/online-art-trade-report/archive.

12 ArtTactic (http://arttactic.com) is an art markets analysis firm based in London.

13 Stable URL: https://www.hiscox.co.uk/sites/uk/files/documents/2019-04/hiscox-online-art-trade-report--2019.pdf, p. 28.

14 While Pownall estimated the value of the global market in 2015 at $\$ 44$ billion, McAndrew calculated its value at $\$ 63.8$ billion; the following year Pownall appraised the value at $\$ 45$ billion, while McAndrew arrived at $\$ 56.6$ billion. See (Pownall 2017; McAndrew 2017). 


\section{Galleries, Dealers and the Internet}

When looking horizontally at the history of art markets over time, and that of galleries in particular, we see that art galleries have always operated in a predominantly urban, brick-and-mortar industry that placed a premium on building unique, personal relations among artists, gallerists and potential clients. One of the recurring problems in gathering research data on gallery sales is the continued lack of transparency and informational asymmetry despite a growing Internet presence. This lack of transparency is not resolved when a gallery assumes partial or total online activity. While inventories are displayed to a larger public and transactions may be made online, the innerworkings of the gallery remain undisclosed. The role of dealer, virtual or not, remains that of an intermediary who selects what is sold, curates, sets prices, facilitates transactions, etc. In this sense, the Internet does not challenge conventional art trade practices; it rather supplements, or complements, by reaching larger publics, practices that have historically been in play in art markets. While an online presence of galleries and dealers is often expected to bring increased transparency and information symmetry both for consumers and researchers, this is rarely the reality, at least not at present.

A notable exception to this observation are South Korean art markets, where galleries are required by law to report their sales results annually. These are kept in the aggregate in publicly, though highly regulated, databases that present a unique opportunity for insights into the South-Korean gallery market. A caveat to this, however, is the unavailability of the raw data for these sales, which are only accessibly as summary tables and charts online. ${ }^{15}$ Galleries remain a marker of preference and one of their key roles lies in nurturing local talent through a multiplicity of platforms. Galleries tend to thrive in collector-dominated markets, since these often produce higher sales prices, even for beginning artists. Private treaty sales in galleries and auction sales inform each other, though here too, galleries lack transparency, even in cases such as the South Korean markets where annual reporting of all sales results is legally required. While galleries and private dealers routinely use all kinds of "price scripts" and auction results to understand price formation and preference as expressed through the marginal willingness to pay, the opposite, is seldom true. ${ }^{16}$

As a result of this lack of publicly accessible data, reports on dealers are dependent upon survey results sourced from private consulting firms. In the 2018 Art Basel Art Market Report, Clare McAndrew, noted the primary issues in gathering data on dealer markets and the consequences this had on analyses resulting from those data. Importantly she notes the limits of using industry data, which are often restricted in terms of their scope and consistency, and the constraints of having to rely on surveys with low response rates and imperfect sampling processes. While work such as this allows us some insight into the magnitude of dealer markets, it is still, as McAndrew makes clear, by no means comprehensive (McAndrew 2018, pp. 342-47).

An additional curious phenomenon worthy of study are expensive paintings sold in brick-and-mortar galleries or at public auction, especially those sold in collector-dominated markets. These can be seen as positional goods that show an inverse relationship between price and demand. They often behave as Veblen goods, a term coined after the American economist and sociologist Thorstein Veblen (1899, chp. 4). Veblen goods are types of luxury goods for which the demand increases as the price increases. This counter-intuitive, and apparent contradiction of the law of demand, results in an upward-sloping demand curve. ${ }^{17}$ In other words, Veblen goods violate the law of demand and after prices have risen above a certain level, demand will also increase. Utility gained might arise from the fact that not many people in society can afford to buy or own such an

15 See: K-Art Martket, https://k-artmarket.kr/member/index.do. In addition, see DALMI working paper on South Korean art markets (Yoon et al. 2018).

16 The term "price scripts" is borrowed from Olav Velthuis, and discussed at great length in his inspiring (Velthuis 2002).

17 Veblen's theory of consumption behavior has not always gained acceptance, both in institutional economics and sociology. An unfortunate effect of this neglect of the Veblen effect has been the marginalization of consumption behavior in economics. See (Dolfsma 2000). 
expensive painting. Considered in this context, brick-and-mortar galleries and auction houses are ideal "third locations," to coin a Starbucks metaphor, in which to create the social environment that engenders conspicuous consumption and social distinction. There is, however, a major problem to test this hypothesis. We simply do not have enough sales data to allow for data-driven research into this phenomenon. This recurring constraint does not allow us to test when law of demand holds in particular art sales and at what price point a painting begins to assume the role of a Veblen good, in the process violating the basic law of demand in microeconomics.

Galleries remain central in branding, creating a "third location" for social positioning, even "Veblenization," if our hypothesis holds. Yet, the relationship between artist and gallery, as well as between the gallery and the prospective buyer(s) also seems to have shifted towards a more autonomously acting artist. The artist active on social media is, in part, a participant in the making of his or her own brand. The role of the gallery has and will continue to be one of the loci for validating artist reputation and the related marginal willingness to pay for a particular artist. Galleries will continue to be a part of this branding, albeit requiring new media skillsets and web presences. Galleries and dealers active on social media, and particularly on Instagram, give the illusion of transparency and even an opening of art markets to new participants, although prices generally remain available only upon request and there are no available data on the actual number of transactions that are made or facilitated via these platforms. Here, again, the Internet serves as an intermediary or a supplement to traditional pathways and practices but does not supplant or fundamentally alter the ways in which art is privately transacted.

A potential innovation are e-commerce platforms, such as Lofty and Catawiki, although, like online-only sales at auction houses, these seem to serve the lower end of art markets better than the upper end. ${ }^{18}$ Segmentation between e-commerce and brick-and-mortar locations (i.e., galleries and auction houses) is especially clear when we consider artists who, in brick-and-mortar contexts, would be associated with Veblen goods. Online, however, these Veblen artists, too, constitute the lower end of art markets. Online sales platforms tend to mimic traditional auction models rather than dealer/gallery models. Lofty, to illustrate just one example, has a dedicated fine arts department and collections devoted to specific artists, but its general inventory is heavily skewed towards the market for collectibles and memorabilia (only a handful of items offered have estimates at or over \$25,000). ${ }^{19}$ The creators of Lofty had originally envisioned an e-commerce platform for the lower end of the fine arts market, modeled off of RubyLane.com, which specialized in antiques and collectibles. Interested sellers would be able to submit photographs and documentation of their objects to experienced appraisers who would, in turn, value the objects and approve or reject them for sale. This is currently the business model being employed by Catawiki. Lofty, however, whose tagline is "The Trusted Marketplace," does not currently offer appraisals, and they only offer items for sale that have been sourced from approved, established auction houses, such as Freeman's.

In addition, Lofty advertises collections of works by notable artists such as Marc Chagall, Pablo Picasso, Keith Haring, and others. Of these artists' work currently shown on Lofty's website, all but one Chagall work has passed (gone unsold), while the highest selling Picasso was a print, which sold for just \$250.00. Keith Haring is somewhat of an exception as a handful of his works have sold for well

18 Lofty and Catawiki are just two examples, which we have studied in detail, of many online art and antiques sales platforms that have implemented vetted online auction environments for fine arts, collectibles and antiques. Over the past decade online auction platforms such as ArtNet, Artsy, 1stdibs, LiveAuctioneers, Singulart, and others have developed. Often constructed on the principles of eBay with auction-like sales environments and "buy-now" options, such platforms have varied vetting processes and sales strategies (at times, as is the case of 1stdibs, adopting a hybrid "bricks-and-clicks" model wherein both an online and brick-and-mortar presence are utilized).

19 On Lofty, as of 24 April 2019, only 25 items total, including both fine art and jewels, had estimates over \$25,000. This is compared to the 15,109 items which had estimates between $\$ 1000$ and $\$ 5000$, which primarily consisted of collectibles and memorabilia. 
above $\$ 25,000$ (the current highest price for a Haring being $\$ 290,000$ ). However, again, the majority of his works on the site have also either passed or have sold at below the $\$ 100$ mark. ${ }^{20}$

In addition to platforms such as Instagram and Artsy, where galleries and dealers are increasingly publicizing inventories and engaging with larger audiences (bit of a show-and-tell model), there are also sites such as Incollect, which describes itself as "a world-class curated marketplace where you can shop the finest furniture, decorative art, fine art, and jewelry by the design masters of the 18th through 21st centuries." ${ }^{21}$ Further claiming that "Over 1000 commission-free listings are posted every Tuesday by the industry's finest dealers. Interior Designers and Architects are invited to join our Trade Program." Here, dealers and galleries may apply to have a page on the site, which is meant to provide "collectors, interior designers and enthusiasts with the absolute best experience for discovering and acquiring art, antiques, jewelry and design." However, as with Artsy, prices are rarely listed and must be inquired about, and some pages are seldom updated. Thus there is no guarantee that the objects shown on the website even remain available for sale. ${ }^{22}$ While Incollect allows vetted dealers/galleries to advertise inventories, and facilitates communication between sellers and potential buyers (requesting prices, emailing, making offers, requesting holds, etc.) it functions more as an additional, albeit somewhat exclusive, social media account. As is the case with other online platforms for transacting or facilitating the transaction of artworks, the results of these social interactions (be they in terms of revenue, total transactions, engagements, etc.) are never made public.

\section{Art Indices}

Given the fact that much of the art markets data available on the Internet are auction prices for artworks, one of the recurring questions in Internet research involving the value of a work of art is focused on whether art should be considered an asset class or a consumption good, or both. ${ }^{23}$ The majority of scholars, especially those in economics, tend to consider art an asset class, whereas sociologists and art markets scholars based in the humanities seem to be a bit more measured and nuanced (Kräussl 2015).

Online research facilitates a focus on price and on art as an asset class. Here, a key approach is to measure financial performances of very specific, attributed works of art over time. The methodological rationale is obvious: market value and marginal willingness to pay (actual price paid for a work of art) are seen as a proxy for measuring how preferences change over time. In order to research this systematically, constructing a repeat sales performance index of works of art is often necessary. Jianping Mei and Michael Moses are two pioneers of this methodology, which is based on hedonic and repeat-sales estimators (Mei and Moses 2002). These two estimation methods are frequently used to construct all kinds of art indices. According to Mei and Moses, a repeat-sales regression (RSR) uses the prices of individual objects traded at two distinct moments in time. If the characteristics of an object do not change (which is the case for works of art), the heterogeneity issue is bypassed, for each art work is, per definition, different. The basic idea of the hedonic regression (HR) method is to regress prices on various attributes of works of art, such as artist, dimension, subject matter, and so on. According to Mei and Moses, the residuals of the regression can be considered as "characteristic-free prices" to compute the price index. However, since the works of art that are part of such an index do not come to the market often, the changes in market value-the marginal willingness to pay-and therefore changes in preference, are not easy to evaluate.

A recurring problem with art indices like Mei-Moses is their selection bias in data gathering, or, in other words, which data they choose to include or exclude. While making a laudable attempt to bring transparency to international art markets, they have always been plagued by the lack of sales data

20 These values are based on information available via Lofty.com as of 24 April 2019.

21 See Incollect, stable URL: https://www.incollect.com.

22 See Third-Party Professionals and Services, stable URL: https://www.incollect.com/terms_of_use.

23 See the pioneering studies by Mandel $(2009,2014)$ and Horowitz $(2011)$. 
available. In addition, art indices such as Mei-Moses rely on data from just half of art markets-the auction market-when an estimated $53 \%$ of art sales globally are actually made up of private gallery and dealer sales. ${ }^{24}$

Mei-Moses focuses exclusively on repeat auction sales made within Christies and Sotheby's, but the index does not account for anything sold in online markets. Further, the index was bought by Sotheby's in 2016 and is no longer available online. ${ }^{25}$ When conducting data-driven research on art markets, it is critical to understand the methodology behind these platforms' data gathering. ArtNet, for instance, uses data from 1600 auction houses and includes online sales results when are available (including what is being sold in ArtNet auctions). ArtNet works with comparable objects rather than resales, while ArtPrice uses the resales model and data from 4500 auction houses (excluding online sales). ${ }^{26}$

\section{Art Fairs}

Art fairs, like galleries, tend to focus on branded (or brandable) artists and high net worth individuals (HNWI), which seems to suggest that, here too, the earlier mentioned "Veblenization" is going on. The social context that art fairs provide helps to create and maintain the trust that is particularly important for valuable, higher quality items that are required for the online market to further develop.

Branding in high-profile art fairs occurs in a very similar manner. Art fairs can bring new buyers into the market by focusing more on local talent and local creative industries. Recent economic and technological trends threaten the viability of this model. Art galleries feel obliged to participate in art fairs, even when it causes significant costs and loss of revenue (Halperin 2017). The art fair has become a very challenging environment that suffers from the same lack of transparency and asymmetrical information regarding price performance. This lack of informational symmetry, regardless of the affordances of the Internet, generates more questions than answers about management practices, performance, and factors affecting success (Smith et al. 2005). The common denominator in many of these studies is the observation that a serious study of the gallery model and its research suffers from a chronic lack of reliable data.

Art fairs tend to project a false sense of transparency by reporting prices at the end of the fair; however, this remains a highly curated and selective list of objects that have been sold from a select group of sellers. ${ }^{27}$ Since these art fairs are intimately connected to private galleries and dealers, prices are largely kept private as well. The relative handful of exceptions that are made public serve to showcase the "success" of the fair itself rather than to report on aggregate statistics. Most researchers working on historical and contemporary art fairs rely on lists of dealers and/or artists who are participating. The primary focus of these studies then tends to be on the geographical origin of the exhibitors and the types of artworks they represent. Additionally, some scholars have utilized firsthand observations. Filip Vermeylen, for example, collected data directly from exhibition stalls at the 2013 India Art Fair in Delhi including tags, red dots, and price lists. Importantly, Vermeylen (2015) noted the variations between the artists advertised in the fair's catalogue and the realities of the exhibition stalls. Such methods are not without their own specific flaws; however, they do emphasize the need for finding and testing alternative methodologies and metrics for measuring art markets phenomena

24 The 2018 Art Basel Art Market Report found that in 2017 dealer sales accounted for approximately 53\% of sales globally. This was based on survey results, interviews and industry data gathered by Arts Economics, a private research and consuling firm founded by Clare McAndrew. See (McAndrew 2018).

25 For more on Sotheby's acquisition of Mei-Moses, see (Maneker 2016; Boucher 2016).

26 Artprice. https://www.artprice.com/indexes/artinvestment.

27 For example, the 2019 sales report from TEFAF lists only a selection of 30 objects sold by 25 exhibitors. Of these, only seven mentioned the final sales price, eight mentioned the asking price and one provided an approximate sales price. See: https://www.tefaf.com/press/press-releases/collector-and-dealer-confidence-precipitates-sales. 
beyond auction markets, especially in instances where scholars have typically encountered a lack of accessible and reliable sales data.

Another constraint which makes it difficult to analyze the impact that the art fair has on actual sales is the moment of the sale. As Rachel Pownall rightly points out, in thinking about sales we should differentiate between sales that are made during the fair and those that are made after the fair ends. While buyers may become interested in artworks or galleries during the fair, it may not be until after the event has concluded that actual transactions are made. This phenomenon should also be taken into account, according to Pownall (2017, p. 54), in how we consider online sales. Similarly, while Internet users globally can interact online with artworks available at galleries, whether or not a transaction occurs online or a simply a new buyer-client relationship is formed initially via the Internet are two separate phenomena.

An important point of overlap to consider is when the art fair attempts to go digital; here, however, the significance of direct social interactions at art fairs and seeing the visit itself as an experience becomes most evident. Digital art fairs that have attempted to mirror the experiences of traditional art fairs online but have generally failed to secure their position in art markets. The first example of a digital art fair was the VIP Art Fair, which took place in January 2011 including virtual boots by 138 contemporary art galleries from 30 countries. This event promised clients private video chats with gallery directors and access to "back rooms," but failed due to its lack of online infrastructure to support these promises (Brown 2011). The second trial a year later, VIP Art Fair 2.0, and a similar event in India, India Art Collective (2011), weren't able to establish the online art fair as a new model (Esman 2010; Maneker 2011).

The popularity of art fairs seems to be on the rise, at least in terms of attendance and the number of events being held annually (be they the art fairs themselves or the many social events held in conjunction to adjacent to art fairs). This is especially for larger franchises such as Art Basel and TEFAF. $^{28}$ Yet, the impact of these fairs on actual art sales or on the development of existing and emerging art markets remains impossible to measure with certainty. This because of both the lack of transparency regarding sales and the vagaries of how we define sales occurring at art fairs or as the result of relationships formed at these and related events.

\section{Concluding Thoughts}

Even when digital platforms imply or even state that their information is fully transparent and easy to access, the examples we've discussed suggest that researchers have little assurance that Internet intermediaries-such as auctions houses, art funds, databases and all kinds of art markets carriers-are not withholding information or biasing the presentation of their data in accordance with commercial interests.

Auction houses such as Sotheby's and Christie's have now fully embraced making their sales results publicly available, but the same cannot be said for eBay-style auction platforms and emergent e-commerce sites for art, where the lack of reliable and consistent data is rampant. This precludes establishing trustworthy art indices or conducting serious data-driven research. As we have seen, art indices also seem to have distinct selection biases in data gathering, not least which data they choose to include as well as what they leave out. Further, as we have seen in the example of Sotheby's acquiring the Mei-Moses art index, relationship serves no other purpose than to improve the auction house's financial interests, whereby access for researchers is not an option.

As to dealers and art galleries, data-driven research is not an option for the moment. Here, too, informational asymmetry rules supreme, excluding approximately $50 \%$ of art markets from serious scholarly scrutiny and applied data-driven research. Here too, the regulatory environment in

28 In October 2016, TEFAF began hosting two additional fairs in New York (fall and spring). Previous to this, in 2002, Art Basel expanded to Miami, and in 2013, to Hong Kong. 
South Korea has created the legal conditions for some additional transparency in the art markets and ultimately, more transparency on the Internet, although this is still quite imperfect.

We have also observed that it remains difficult to predict the future of online art markets, though it is obvious that over the past ten years online market platforms have been gaining in importance, particularly in lower market segments. The existence of online preference algorithms (i.e., Artsy) offers new opportunities to familiarize oneself with new artists and hitherto unknown artworks. Yet, the often observed "boom" in the online art trade, or assumption that the Internet will somehow fundamentally alter how we buy and sell art needs further research and nuance. Based on our current research, it is one of our working hypotheses that many online sales are probably serving (and enhancing) demand in market segments for cheaper works of art, compared to those offered for sale in brick-and mortar auctions, galleries and art fairs.

The earlier mentioned hybrid model of a combined brick-and-mortar and online presence seems to be a viable risk averse strategy to enhance demand. It is only when, however, serious efforts are made to collect sales data in the aggregate, on a large scale and in publicly accessible online platforms that we will we be able to assess with a higher degree of precision how, where and when price and preference formation actually works. In other words, these online sales do not threaten the traditional models, but actually segment the demand. While data on private sales, online as well as offline, remain undisclosed, data on the emerging online auction markets are gradually becoming more available. From those data, which are now attainable for big name auction houses such as Christie's and Sotheby's, we see that the online art trade is growing, though, once again, not seriously threatening to replace brick-and-mortar sales. At present, they often seem to complement each other.

As to art markets scholarship, serious efforts need to be made to collect sales data in the aggregate, on a large scale and in publicly accessible online platforms with a higher degree of informational transparency, trust and reliability. By way of a concluding thought, a desired hermeneutic payoff is that art markets, as objects of inquiry, need to be studied in the aggregate, not only with new sets of questions and new methods in mind, but also with a sense of urgency that more transparency, whether implemented through voluntary self-regulation or through legislation, is indeed a priority for both scholars and buyers.

Author Contributions: This collaborative article between H.J.V.M., K.P.A. and F.L. resulted from a sustained cross-disciplinary approach and integrated economics-art history teaching and research practice in the History of Art Markets as part of the Duke Art, Law and Markets Initiative (DALMI) at Duke University.

Funding: This research received no external funding.

Conflicts of Interest: The authors declare no conflict of interest.

\section{References}

Ali, Doha, Erin McDermott, Noah Michaud, and Mitchell Parekh. 2019. Online Auctions at Christie's \& Sotheby's. DALMI Working Paper on Art \& Markets no. 19213. Available online: https://www.dukedalmi.org/wpcontent/uploads/19213-Working-Paper.pdf (accessed on 30 April 2019).

Arora, Payal, and Filip Vermeylen. 2013. The end of the art connoisseur? Experts and knowledge production in the visual arts in the digital age. Information, Communication $\mathcal{E}$ Society 16: 194-214. [CrossRef]

Ashenfelter, Orley, and Kathryn Graddy. 2006. Art Auctions. In Handbook of the Economics of Art and Culture. Edited by Victor Ginsburgh and David Throsby. Amsterdam: Elsevier, pp. 909-42.

Blouin Art Sales Index (BASI). 2019. Available online: https://www.blouinartsalesindex.com/site/app.ai (accessed on 22 April 2019).

Boucher, Brian. 2016. See What Experts Have to Say About Sotheby's Acquisition of the Mei-Moses Art Indices. Artnet News. October 29. Available online: https://news.artnet.com/market/sothebys-acquisition-MeiMosesart-indices-725648 (accessed on 30 April 2019).

Brown, Griselda Murray. 2011. VIP Art Fair: A virtual failure? Financial Times. February 4. Available online: https://www.ft.com/content/a34be1d2-2eb5-11e0-9877-00144feabdc0 (accessed on 30 April 2019). 
De Marchi, Neil, and Hans J. Van Miegroet. 2006a. History of Art Markets. In Handbook on the Economics of Art and Culture. Amsterdam, London and Tokyo: Elsevier Science, vol. 1, pp. 69-122.

De Marchi, Neil, and Hans J. Van Miegroet, eds. 2006b. Mapping Markets for Paintings in Early Modern Europe 1450-1750. Turnhout: Brepols.

Dolfsma, Wilfred. 2000. Life And Times of the Veblen Effect. History of Economic Ideas 8: 61-82.

Esman, Abigail R. 2010. VIP Artfair Bombs Again: A Lesson in Art Marketing and Online Sales. Forbes Magazine, February 14.

Frey, Bruno S. 2003. Art \& Economics. Berlin and New York: Springer.

Gerlis, Melanie. 2018. Condo Dealers Connect-As Tefaf Report is Cancelled. Financial Times. January 19. Available online: https://www.ft.com/content/f50f9c70-fc3a-11e7-9bfc-052cbba03425 (accessed on 30 April 2019).

Ginsburgh, Victor, and David Throsby, eds. 2006. Handbook on the Economics of Art and Culture. Amsterdam, London and Tokyo: Elsevier Science, vol. 1.

Ginsburgh, Victor, and David Throsby, eds. 2014. Handbook on the Economics of Art and Culture. Oxford: North Holland, vol. 2.

Halperin, Julia. 2017. Art-Fair Economics: Why Small Galleries do Art Fairs Even When They Don't Make Money. Available online: https://news.artnet.com/about/julia-halperin-605 (accessed on 30 April 2019).

Horowitz, Noah. 2011. Art of the Deal: Contemporary Art in a Global Financial Market. Princeton: Princeton University Press, pp. 143-87.

Hulst, Titia. 2017. Art Markets. In A Sourcebook of Writings on Artists, Dealers and Markets. Oakland: University of California Press.

Hutter, Michael, and Richard Shusterman. 2006. Value and the Valuation of Art in Economic and Aesthetic Theory. In Handbook on the Economics of Art and Culture. Amsterdam, London and Tokyo: Elsevier Science, vol. 1, pp. 169-208.

Kazakina, Katya. 2016. Want to Sell a \$24 Million Painting Fast? Instagram for the Win. Bloomberg. December 21. Available online: https:/www.bloomberg.com/news/articles/2016-12-21/want-to-sell-a-24-million-paintingfast-instagram-for-the-win (accessed on 30 April 2019).

Kräussl, Roman. 2015. Art as an Alternate Asset Class: Risk and Return Characteristics of the Middle Eastern and Northern African Art Markets. In Cosmopolitan Canvases: The Globalization of Markets for Contemporary Art. Edited by Olav Velthuis and Stefano Baia Curioni. Oxford: Oxford University Press, pp. 147-69.

Mandel, Benjamin. 2009. Art as an Investment and Conspicuous Consumption Good. American Economic Review 99: 1653-63. [CrossRef]

Mandel, Benjamin. 2014. Investment in Visual Art: Evidence form International Transactions. In Handbook on the Economics of Art and Culture. Oxford: North Holland, vol. 2, pp. 233-60.

Maneker, Marion. 2011. India Gets Another Art Fair. Art Market Monitor. September 14. Available online: https: //www.artmarketmonitor.com/2011/09/14/india-gets-another-art-fair-online/ (accessed on 30 April 2019).

Maneker, Marion. 2016. Sotheby's Mei-Moses Purchase Brings Remembrance of Indices Past. Art Market Monitor. October 28. Available online: https://www.artmarketmonitor.com/2016/10/28/sothebys-mei-moses-purchasebrings-remembrance-of-indices-past/ (accessed on 30 April 2019).

McAndrew, Clare. 2017. The Art Market. Basel: Art Basel and UBS.

McAndrew, Clare. 2018. The Art Market. Basel: Art Basel and UBS.

McLaughlin, Margaret. 1996. The Art Site on the World Wide Web. Journal of Computer-Mediated Communication 1 : JCMC146. [CrossRef]

Mei, Jianpin, and Michael Moses. 2002. Art as an Investment and the Underperformance of Masterpieces. American Economic Review 92: 1656-68. [CrossRef]

Pasquale, Frank. 2010. Beyond Innovation and Competition: The Need for Qualified Transparency in Internet Intermediaries. Northwestern University Law Review 99: 105-73. [CrossRef]

Pownall, Rachel. 2017. TEFAF Art Market Report. Maastricht: The European Fine Art Foundation.

Pownall, Rachel A. J., and Leonard Wolk. 2013. Bidding behavior and experience in Internet auctions. European Economic Review 61: 14-27. [CrossRef]

Smith, Howard L., Richard Discenza, and Kenneth G. Baker. 2005. Building Sustainable Success in Art Galleries: An Exploratory Study of Adaptive Strategies. Journal of Small Business Strategy 16: 29-42. 
Soboleva, Elena. 2015. 7 Ways to Win Over Collectors on Instagram. Artsy. May 15. Available online: https: //www.artsy.net/article/elena-soboleva-7-ways-to-win-over-collectors-on-instagram (accessed on 30 April 2019).

Throsby, David, and Anita Zednik. 2014. The Economic and Cultural Value of Paintings. Some Empirical Evidence. In Handbook on the Economics of Art and Culture. Oxford: North Holland, vol. 2, pp. 81-99.

Towse, Ruth, ed. 2011. A Handbook of Cultural Economics. Cheltenham: Edward Elgar.

Van Ginhoven, Sandra. 2016. Connecting Art Markets: Guilliam Forchondt's Dealership in Antwerp (c.1632-78) and the Overseas Paintings Trade. Leiden: Brill Publishers.

Veblen, Thorstein. 1899. Conspicuous Consumption. In Theory of the Leisure Class: An Economic Study in the Evolution of Institutions. New York: Mc Millan. [CrossRef]

Velthuis, Olav. 2002. Talking Prices: Symbolic Meanings of Prices on the Market for Contemporary Art. Princeton: Princeton University Press.

Velthuis, Olav. 2011. Art Markets. In A Handbook of Cultural Economics, 2nd ed. Edited by Ruth Towse. Cheltenham: Edward Elgar, pp. 33-42.

Velthuis, Olav. 2013. Globalization of Markets for Contemporary Art. Why local ties remain dominant in Amsterdam and Berlin. Journal European Societies 15: 290-308. [CrossRef]

Velthuis, Olav, and Erica Coslor. 2012. The Financialization of Art. In The Oxford Handbook of the Sociology of Finance. Edited by Karin Knorr Cetina and Alex Preda. Oxford: Oxford University Press, pp. 471-87.

Vermeylen, Filip. 2006. Painting for the Market: Commercialization of Art in Antwerps Golden Age. Turnhout: Brepols. Vermeylen, Filip. 2015. The India Art Fair and the Market for Visual Arts in the Global South. In Cosmopolitan Canvases: The Globalisation of Markets for Contemporary Art. Edited by Olav Velthuis and Stefano Baia Curioni. New York: Oxford University Press, pp. 31-54.

Yoon, Soohyun, Drew Johnson, and Anna Kropf. 2018. The South Korean Art Markets: Consumer Preference and Auction Strategies. DALMI Working Paper on Art \& Markets no. 18221. Available online: https: //www.dukedalmi.org/wp-content/uploads/18221-Working-Paper.pdf (accessed on 30 April 2019).

(C) 2019 by the authors. Licensee MDPI, Basel, Switzerland. This article is an open access article distributed under the terms and conditions of the Creative Commons Attribution (CC BY) license (http://creativecommons.org/licenses/by/4.0/). 